\title{
The discriminative capacity of CBCL/11/2-5 -DSM5 scales to identify disruptive and internalizing disorders in preschool children.
}

\begin{abstract}
This paper studies the discriminative capacity of CBCL/1 1/2-5 (Achenbach \& Rescorla, 2000) DSM5-scales Attention-Deficit and Hyperactivity Disorder (ADHD), Oppositional Defiant Disorder (ODD), Anxiety and Depressive Problems for detecting the presence of DSM5 (APA, 2013) disorders, ADHD, ODD, Anxiety and Mood disorders, assessed through diagnostic interview, in children aged three to five. Additionally, we compare the clinical utility of the CBCL/11/2-5 DSM5 scales with respect to analogous CBCL/11/2-5 syndrome scales. A large community sample of 616 preschool children was longitudinally assessed for the stated age group. Statistical analysis was based on ROC procedures and binary logistic regressions.

ADHD and ODD CBCL/1 ${ }^{1 / 2}-5$-DSM5 scales achieved good discriminative ability to identify ADHD and ODD interview's diagnoses, at any age. CBCL/1 ${ }^{1 / 2}-5$-DSM5 Anxiety scale discriminative capacity was fair for unspecific Anxiety Disorders in all age groups. CBCL/11/2-5 -DSM5 depressive problems scale showed the poorest discriminative capacity for mood disorders (including depressive episode with insufficient symptoms), oscillating into the poor-to-fair range. As a whole, DSM5-oriented scales generally did not provide evidence better for discriminative capacity than syndrome-scales in identifying DSM5 diagnoses. CBCL/1 1/2-5 -DSM5 scales discriminate externalizing disorders better than internalizing disorders for ages 3 to 5. Scores on the ADHD and ODD CBCL/1/2-5-DSM5 scales can be used to screen for DSM5 ADHD and ODD disorders in general populations of preschool children.
\end{abstract}




\section{DISCRIMINATIVE CAPACITY OF CBCL/11/2-5 -DSM5 SCALES}

Keywords: CBCL/1²/2-5, disruptive disorders, DSM5-oriented scales, internalizing disorders, preschoolers. 


\section{Introduction}

Given the need for evidence-based studies of emotional and conduct problems in child psychopathology, the instruments of the Achenbach System of Empirically Based Assessment (ASEBA; Achenbach, 2009) have become the most widely used both in clinical and research settings in many countries and languages. The ASEBA assesses competencies, adaptive functioning, and behavioral, emotional and social problems from the age of $1 \frac{1 / 2}{2}$ to over 90 , using a combination of exploratory and confirmatory factor analyses to empirically derive syndromes.

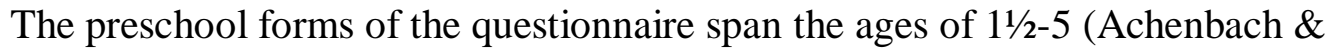
Rescorla, 2000). Specifically, the Child Behavior Checklist (CBCL/1/2-5) is addressed at parents or caregivers. This instrument has been proven to provide strong psychometric properties across cultures (Ivanova et al., 2010; Rescorla et al., 2007).The empirically derived scales for the preschooler version include Emotionally Reactive, Anxious/Depression, Somatic Complaints, Withdrawn, Sleep Problems, Attention Problems and Aggressive Behavior (Rescorla, 2005). A second order-factor analysis yields the two global groupings labeled "Externalizing" and "Internalizing", which are similar to those found in the earlier children's versions. A total score for the items is also derived as a measure of global-problem behavior.

Besides accumulated empirical evidence from empirically derived scales, the lack of utility in the measurement of particular diagnoses as proposed in the DSM system has been considered a limitation. In order to provide a perspective with closer linkage to the DSM nosology, the DSM oriented scales were developed (Achenbach \& Dumenci, 2001; Achenbach, Dumenci, \& Rescorla, 2003). Unlike the originals, these scales were not empirically derived but, rather, were created through consensus among sixteen specialists from ten cultures (Rescorla, 2005). They rated each item as not consistent (0), somewhat 
consistent (1) or very consistent (2) with nine DSM diagnostic categories. Agreement of at least 10 out of 16 specialists was required in order to validate that an item was consistent for inclusion in the DSM-oriented scales. The nine initial categories were finally reduced to five, due to overlaps in DSM diagnostics or the problem items. The five DSM-oriented scales and the corresponding DSM5 diagnoses they were meant to represent were: Depressive Problems (including Major Depressive Disorder, MDD and Dysthymic Disorder, DD); Anxiety Problems (Generalized Anxiety Disorder, GAD; Separation Anxiety Disorder, SAD; Specific Phobia, SSP and Social Phobia, SP); Attention-Deficit and Hyperactivity Problems (including Hyperactive-Impulsive and Inattentive types); Oppositional Defiant Problems (Oppositional Defiant Disorder and Conduct Disorder) and Pervasive Developmental Problems (including Asperger's Disorder). Compared to the syndrome scales, these showed similar psychometric properties with regard to consistence, reliability and cross-informant agreement (Achenbach et al., 2003; Nakamura, Ebesutani, Bernstein, \& Chorpita, 2009).

Recently, in order to adapt the scales to the new DSM5 (APA, 2013), the CBCL-DSM oriented scales have been reformulated (Achenbach, 2013). The former Pervasive Developmental Problems has been replaced by the new Autism Spectrum Problems scale, which comprises items identified by experts as highly consistent with DSM5 criteria for Autism Spectrum Disorder. The revised Anxiety Problems scale comprises age-appropriate items identified by the experts as highly consistent with DSM5 criteria for GAD, SAD, SSP and Social Anxiety Specific Phobia (SASP). The other scales are left unchanged from the DSM-IV to DSM5 version. There is little knowledge of the psychometrical properties in the CBCL-DSM scales or of their incremental validity over the syndrome scales (Ebesutani et al., 2010). This is especially true for the preschool form of the questionnaire (Kristensen, Solvejg Henriksen,Tine Bilenberg, Niels, 2010) and for the DSM-oriented externalizing scales (Oppositional Problems and Conduct Problems scales), as well as for the Attention 
Deficit/Hyperactivity Problems scale (Ebesutani et al., 2010). Present-day data are completely inexistent for any version of the new DSM5. To our knowledge, no study has reported on DSM-Oriented scales in preschool ages with large community samples. There is an essential need to contrast the clinical utility of the widely used instruments.

Studying a clinical sample with the school form of CBCL/6-18, Ferdinand (2008) obtained a moderate predictive validity for the anxiety scale with respect to the corresponding SAD, GAD or SPP DSM-IV disorders, and good validity for the affective problems scale when predicting MDD or DYS DSM-IV diagnoses obtained with a semi-structured interview. Furthermore, using CBCL/6-18 in a clinically referred sample Ebesutani et al., (2010) concluded that DSM-oriented scales did not add incremental clinical utility to the syndrome scales with respect to corresponding diagnoses when also using a semi-structured interview answered by parents. The former was true for all scales except for Anxiety Problems compared to the Anxious/Depressed syndrome scale. Furthermore, a study of a clinically referred sample of 8-17 year-old children (Ebesutani et al., 2010; Lacalle, Ezpeleta, \& Domenech, 2012) concluded that DSM-oriented scales were a useful tool for estimating DSM-IV disorders; they also obtain better results for DSM-scales when referring to Disruptive Disorders. These conclusions were the same as those obtained by (Bellina et al., 2013) in a sample of 6-16 year old referred children. Good convergent and discriminative validity was found by (Nakamura et al., 2009) in a clinical sample of adolescents.

The purpose of this study was to test the discriminative capacity of CBCL/11/2-5 (Achenbach \& Rescorla, 2000) DSM5 scales for identifying the DSM5 disorders ADHD, ODD, Anxiety and Mood disorders in children aged three to five, and to compare its clinical utility with the analogous CBCL/11/2-5 syndrome scales. The fact that the DSM5-oriented 
scales are shorter than the originals would make them more suitable for screening purposes if they showed the expected good discriminative capacity.

\section{Method}

\section{Participants}

Data used in this work correspond to a longitudinal study of behavioral problems in preschool children (Ezpeleta, de la Osa, \& Domènech, 2011). The research began with a twophase design, with an initial random sample of 2,283 children selected from the census of preschoolers (3 years old) in Barcelona in the 2009-10 academic year.

The percentage of participants in the first phase (screening) was $58.7 \%(N=1,341$ families) and no differences emerged for sex $(p=.95)$ when comparing participants and refusals. However, the proportion of refusals was statistically higher for families in low socioeconomic groups (Ezpeleta et al., 2011) $(p<.001)$. Screening for child inclusion in the second phase was carried out with the parents' version of the Strengths and Difficulties Questionnaire for 3 and 4 years old $\left(\mathrm{SDQ}^{3-4}\right.$; (Goodman, 1997). A random sample including (a) $30 \%$ of children with negative scores in the screening and (b) all children with a positive screening score was invited to continue with the longitudinal research. The final second phase sample included $89.4 \%$ of the families asked to continue ( $N=622$ children) and no statistical differences were found when participants and refusals were compared for sex $(p=.820)$ or type of school $(p=.850)$. Children's mean age was $3.0(S D=0.16) ; 310$ were boys $(49.8 \%)$.

The sample in this study corresponds to all preschool children with CBCL/1 $1 \frac{2-5}{2}$ questionnaire available at ages 3,4 or $5(N=616)$. Specifically, at age 3, CBCL/11/2-5 was available for $n=616$ children, at age 4 for $n=602$ and at age 5 for $n=545$. No statistical 
differences as regard age $(p=.063)$ or sex $(p=.163)$ were found between those remaining in the study and those dropping out of the second or third follow-up. Sociodemographical variables for the $N=616$ participants at intake and weighted prevalence of DSM-IV disorders are described in Tables 1 and 2. Children showing intellectual disability, pervasive developmental disorders, families with language difficulties, without a primary caretaker who could report on the child, or were moving over the next year to another location were excluded (75 individuals).

\section{INSERT TABLE 1 AND TABLE 2}

\section{Measures}

The Child Behavior Checklist (CBCL $1^{1 / 2}-5$; Achenbach \& Rescorla, 2000) was used to measure behavioral and emotional problems dimensionally. CBCL $1^{1 / 2}-5$ includes a set of 99 items with 3 response options (0: not true, 1: somewhat or sometimes true, 2: very true or often true), plus one open-ended item for adding problems that are not listed on the form. Raw scores were analyzed for syndrome and DSM5-oriented scales, as well as for original syndrome scales (Achenbach, 2013). Internal consistency in the sample covered the range moderate to good (Table 3 includes alpha-coefficients for ages 3-4-5).

The Diagnostic Interview of Children and Adolescents for Parents of Preschool Children and Young Children (DICA-PPYC; Ezpeleta, de la Osa, Granero, Domènech, \& Reich, 2011) was used to assess children's psychopathology according to DSM-IV-TR taxonomy (American Psychiatric Association, 1994). Adaptation and validation for the Spanish preschool population showed sound psychometric properties (Ezpeleta et al., 2011). The diagnoses included in this study are presented in Table 2. With the information recruited in the interview it was possible to generate the diagnosis of the following DSM5 disorders: 
ADHD, ODD, CD, Major depression (including depressive episode with insufficient symptoms), SAD, GAD and specific phobias

\section{Procedure}

The project was approved by the ethics review committee at the authors' institution. Families were recruited at the schools and gave written consent. All families of children in P3 (first level of preschool school grade, 3-year-olds) at the participating schools were invited to answer the $\mathrm{SDQ}^{3-4}$. Families who agreed and met the screening criteria were contacted by telephone and interviewed at the school for each assessment. Interviewers were trained and were blind to screening group. After the interview, parents filled the CBCL/1/2-5.

\section{Statistical analysis}

Analyses were carried out with SPSS20 for windows. Due to the multi-sampling design, Complex Samples system was used for statistical analysis, defining a project design with sampling weights inversely proportional to the probability of selection at stage two of the longitudinal project.

ROC procedures and binary logistic regressions (adjusted by covariate children's age and other comorbidities to those analyzed) measured the capacity of CBCL to discriminate the presence of DSM disorders assessed through diagnostic interview. The Area Under The Receiver Operator Curve (AUC) estimated the discriminative capacity of CBCL and the Nagelkerke's pseudo- $\mathrm{R}^{2}$ estimated the predictive ability. According to the rough guide for classifying the accuracy of a diagnostic-screening test, AUC under 0.60 were considered fail, 0.60-0.70 poor, $0.70-0.80$ moderate, $0.80-0.90$ good and $0.90-1$ excellent. The diagnoses analyzed in this study have been generated using DSM5 criteria, as the information in the 
interview allowed to do so. The DSM5-oriented scales and the (corresponding DSM5) diagnoses they are meant to represent included in the analysis were: Affective Problems (MDD), Anxiety Problems (GAD, SAD and SSP); ADHD and Conduct Problems (ODD and CD). In the former case, Oppositional Defiant Disorder scale was related to two different DSM diagnoses, ODD and CD. Each model was adjusted by sex and presence of any other diagnoses.

\section{Results}

Table 3 shows the results for the discriminative capacity (measured through the AUC values) and the predictive ability (estimated through $\mathrm{R}^{2}$ coefficients) of the CBCL $1^{1 / 2}-5$ to identify DSM5 disorders measured through diagnostic interview, separately at 3-4-5 years of age. Results were obtained for binary logistic regressions adjusted by children's sex and the presence of other DSM5 comorbid disorders, defining the presence of DSM5 disorders as the outcome/criterion, and including the CBCL $1^{1 / 2}$-5-syndrome or CBCL $1^{1 / 2}$-5-DSM5 oriented scales as the incomes. As a whole, ADHD and ODD CBCL $1^{1 / 2}-5-$ DSM5-oriented scales scores obtained good to excellent discriminative accuracy at any age for ADHD (AUC between .836 and .901) and good for ODD (AUC between .854 and .881 ). The discriminative capacity for the parallel syndrome scales was within the range good to excellent (AUC from .819 to .905$)$ and good (AUC .845 to .876) for the ADHD and ODD disorders. ODD DSM5oriented scale also showed an excellent capacity to identify DSM5 Conduct Disorder diagnosis at ages 4 and 5 (AUC .920). Discriminative capacity of the anxiety scale was good (AUC from .710 to .801) for unspecific Anxiety Disorders in all age groups. The Depressive problems CBCL/1 1/2-5-DSM5 scale showed poorest discriminative capacity for DSM5 Mood disorders (including depressive episode with insufficient symptoms), with AUC coefficients within the range poor (.630) to fair (.729). For CBCL/11/2-5 -syndrome scales, Attention 
problems at age 3 and 4, Aggressive behavior at age 4 for ODD and at any age for CD and Anxious-depressed at age 5 discriminated better than the counterpart CBCL/11/2-5DSM5scale.

Only CBCL/1 1/2-5DSM5-Depressive Problems scale discriminated better than the CBCL/11/2-5-syndrome-Anxious-Depressed scale at ages 3 and 4. However, although the different discriminative capacity, differences between the CBCL/11/2-5-DSM5 scales and their counterpart CBCL/11/2-5 -syndrome scales were very small (differences in AUC were lower than 0.10).

INSERT TABLE 3 ABOUT HERE

\section{Discussion}

The results allow us to conclude that CBCL/11/2-5-DSM5-oriented scales are generally valid for discriminating related DSM5-diagnoses in preschool years. At ages three to five, they better discriminate externalizing than internalizing disorders. These results are consistent with those found by other researchers using the child and adolescent version (CBCL 6-18) of the questionnaire and DSM-IV criteria (Bellina et al., 2013; Ebesutani et al., 2010; Lacalle et al., 2012). Our results show that ADHD DSM5-oriented scales are not a better predictor of ADHD diagnostic than the syndrome scale at preschool ages. This is discordant with (Aebi, Metzke, \& Steinhausen, 2010) studying a sample of 6-17 year-old outpatients. Remarkably, the ODD DSM5- oriented scale better discriminates DSM5 Conduct Disorder than Oppositional Defiant Disorder at ages four and five. Other authors have found the same using CBCL/6-18 with clinically referred samples (Ebesutani et al., 2010). This result, probably related to the comorbidity of certain symptoms between the two conditions indicates that the DSM5-oriented scales cannot discriminate between the two categories. In 
the presence of high scores in the ODD DSM5-oriented scale, a condition of Conduct Disorder should also be considered.

The anxiety scale fairly predicted unspecific Anxiety Disorders in all the groups. The depressive problems CBCL/1/2-5 -DSM5 scale showed the poorest prediction ability for Mood disorders. Only the depressive Problems' DSM5-scale predicts better than the AnxiousDepressed syndrome scale at age 4. Different studies with older children (Ferdinand, 2008) have also questioned the validity of CBCL to indicate presence of anxiety problems in the manner of DSM nosology. Other authors have found associations between internalizing syndromes and DSM diagnosis pertaining to anxiety and depression to be weaker and less specific (Wolff, Vogels \& Reijneveld, 2014). In the same sense and working with adults Dingle, et al., (2011) reported that the DSM-oriented scale Depression did not perform better than the empirical Anxious/Depressed scale in identifying young adults with DSM depressive disorder.

Scores on the ADHD and ODD CBCL/11/2-5-DSM5 scales can be used to screen for DSM5 ADHD, ODD and CD in general populations of preschool children. DSM5-oriented scales generally did not provide evidence of performance superior to that of the syndromescales as regards correspondence with DSM5 diagnostics. In keeping with what occurs for older children and adolescents, DSM5-oriented scales do not add incremental clinical utility above the syndrome scales (Ebesutani et al., 2010). Although they do not represent a major advantage over the previous syndrome scales, the smaller number of items (just 44 for the DSM5-oriented scales) means that these scales would be a good screening tool, especially for externalizing disorders and making clinical tasks more efficient.

This is the first study to report on the discriminative capacity of CBCL/1 1/2-5-DSM5 scales in a large sample of preschoolers. We were unable to study the six scales in their 
entirety due to the low prevalence of pervasive in the sample community. Further studies are required to gain fuller insight into about the utility of CBCL/11/2-5-DSM5-directed towards referred samples, or the clinical differences between children detected by DSM scales vs. syndromes' scales, but our results support the idea that DSM5-oriented scales allow early identification in general population of children with behavioral-emotional problems, thereby enabling them to obtain the assistance that they need.

\section{Acknowledgments}

Funding was from the Spanish Ministry of Science and Innovation (grant PSI2009-07542) and the Spanish Ministry of Economy and Competitiveness (grant PSI2012-32695). We acknowledge all families and schools participating in the study. 


\section{References}

Achenbach, T. M. (2009). The Achenbach System of Empirically Based Assessemnt (ASEBA): Development, Findings, Theory, and Applications. Burlington, VT: University of Vermont Research Center for Children, Youth and Families.

Achenbach, T. M. (2013). DSM Guide for the ASEBA. Burlington, VT: University of Vermont, Research Center for Children, Youth \& Families.

Achenbach, T. M., \& Dumenci, L. (2001). Advances in empirically based assessment:

Revised cross-informant syndromes and new DSM-oriented scales for the CBCL, YSR, and TRF: Comment on lengua, sadowksi, friedrich, and fisher (2001). Journal of Consulting and Clinical Psychology, 69(4), 699-702. doi:10.1037//0022-006X.69.4.699

Achenbach, T. M., Dumenci, L., \& Rescorla, L. A. (2003). DSM-oriented and empirically based approaches to constructing scales from the same item pools. Journal of Clinical Child and Adolescent Psychology, 32(3), 328-340. doi:10.1207/S15374424JCCP3203_02

Achenbach, T. M., \& Rescorla, L. A. (2000). Manual for the ASEBA preschool-age forms \& profiles. Burlington, VT: University of Vermont, Research Center for Children, Youth, \& Families.

Aebi, M., Metzke, C. W., \& Steinhausen, H. (2010). Accuracy of the DSM-oriented attention problem scale of the child behavior checklist in diagnosing attention-deficit hyperactivity disorder. Journal of Attention Disorders, 13(5), 454-463.

doi:10.1177/1087054708325739

American Psychiatric Association. (1994). DSM-IV diagnostic and statistical manual of mental disorders. Washington, DC: APA.

American Psychiatric Association. (2013). DSM5 diagnostic and statistical manual of mental disorders. Arlington,VA: APA. 
American Psychiatric Association. (2000). DSM-IV-TR Diagnostic and Statistical Manual of Mental Disorders Text Revised. $4^{\text {th }}$ Ed. Washington, DC: APA.

Bellina, M., Brambilla, P., Garzitto, M., Negri, G. A. L., Molteni, M., \& Nobile, M. (2013). The ability of CBCL DSM-oriented scales to predict DSM-IV diagnoses in a referred sample of children and adolescents. European Child \& Adolescent Psychiatry, 22(4), 235-246. doi:10.1007/s00787-012-0343-0

Ebesutani, C., Bernstein, A., Nakamura, B. J., Chorpita, B. F., Higa-McMillan, C. K., Weisz, J. R., \& Res Network Youth Mental Hlth. (2010). Concurrent validity of the child behavior checklist DSM-oriented scales: Correspondence with DSM diagnoses and comparison to syndrome scales. Journal of Psychopathology and Behavioral Assessment, 32(3), 373-384. doi:10.1007/s10862-009-9174-9

Ezpeleta, L., de la Osa, N., \& Domènech, J. M. (2013) Prevalence of DSM-IV disorders, comorbidity and impairment in 3-year-old spanish preschoolers. Social Psychiatry and Psychiatric Epidemiology doi: 10.1007/s00127-013-0683-1.

Ezpeleta, L., de la Osa, N., Granero, R., Domènech, J. M., \& Reich, W. (2011). The diagnostic interview of children and adolescents for parents of preschool and young children: Psychometric properties in the general population. Psychiatry Research, 190, 137-144. doi:10.1016/j.psychres.2011.04.034

Dingle, K. Clavarino, A., Williams, G.M., Bor, W.W., Najman, J.M. \& Alati, R. (2011). Predicting depressive and anxiety disorders with the YARS internilizing scale (empirical and DSM-oriented). Social Psychiatry and Psychiatric Epidemiology, 46, 1313-1324.

Ferdinand, R. F. (2008). Validity of the CBCL/YSR DSM-IV scales anxiety problems and affective problems. Journal of Anxiety Disorders, 22(1), 126-134.

doi:10.1016/j.janxdis.2007.01.008 
Goodman, R. (1997). The strenghs and difficulties questionnaire. Journal of Child Psychology and Psychiatry, 38, 581-586.

Hollingshead, A. B. (1975). Four factor index of social status.. Unpublished manuscript. Ivanova, M. Y., Achenbach, T. M., Rescorla, L. A., Harder, V. S., Ang, R. P., Bilenberg, N.\& Verhulst, F. C. (2010). Preschool psychopathology reported by parents in 23 societies: Testing the seven-syndrome model of the child behavior checklist for ages 1.5-5. Journal of the American Academy of Child and Adolescent Psychiatry, 49(12), 1215-1224. doi:10.1016/j.jaac.2010.08.019

Kristensen, Solvejg Henriksen,Tine Bilenberg \& Niels. (2010). The child behavior checklist for ages 1.5-5 (CBCL/1(1/2)-5): Assessment and analysis of parent- and caregiverreported problems in a population-based sample of danish preschool children. Nordic Journal of Psychiatry, 64(3), 203-9. doi:10.3109/08039480903456595

Lacalle, M., Ezpeleta, L., \& Domenech, J. M. (2012). DSM-oriented scales of the child behavior checklist and youth self-report in clinically referred spanish children. Spanish Journal of Psychology, 15(1), 377-387. doi:10.5209/rev_.2012.v15.n1.37344

Nakamura, B. J., Ebesutani, C., Bernstein, A., \& Chorpita, B. F. (2009). A psychometric analysis of the child behavior checklist DSM-oriented scales. Journal of Psychopathology and Behavioral Assessment, 31(3), 178-189. doi:10.1007/s10862-008$9119-8$

Reich, W., \& Ezpeleta, L. (2009). Entrevista diagnóstica para niños y adolescentes - versión para padres de preescolares (3-7 años). manuscrito no publicado, Unpublished manuscript.

Rescorla, L. A. (2005). Assessment of young children using the achenbach system of empirically based assessment (ASEBA). Mental Retardation and Developmental Disabilities Research Reviews, 11(3), 226-237. doi:10.1002/mrdd.20071 
Rescorla, L., Achenbach, T., Ivanova, M. Y., Dumenci, L., Almqvist, F., Bilenberg, N., . . .

Verhulst, F. (2007). Behavioral and emotional problems reported by parents of children ages 6 to 16 in 31 societies. Journal of Emotional and Behavioral Disorders, 15(3), 130142. doi: $10.1177 / 10634266070150030101$

de Wolff, M.S., Vogels, A.G.C. \& Reijneveld, S.A (2014). The empirical versus DSM-

Oriented Approach of the Child Behavior Checklist. European Journal of Psychological Assessment, 30 (1), 22.30. 
Discriminative capacity of CBCL/11/2-5 -DSM5 scales

Table 1. Sociodemographics for sample $(n=616)$.

\begin{tabular}{llrl}
\hline Sex (male); $n(\%)$ & & 308 & $50.0 \%$ \\
Ethnicity; $n(\%)$ & Caucasian & 549 & $89.1 \%$ \\
& African & 1 & $0.2 \%$ \\
& American-hispanic & 39 & $6.3 \%$ \\
& Asian & 6 & $1.0 \%$ \\
& Other & 21 & $3.4 \%$ \\
& High & 202 & $32.8 \%$ \\
& Mean-High $n(\%)$ & 194 & $31.5 \%$ \\
& Mean & 88 & $14.3 \%$ \\
& Mean-Low & 97 & $15.7 \%$ \\
& Low & 35 & $5.7 \%$ \\
\hline
\end{tabular}

${ }^{\mathrm{T}}$ Socioeconomic status (Hollingshead, 1975) 
Discriminative capacity of CBCL/11/2-5 -DSM5 scales

Table 2. Prevalence of DSM disorders for the sample.

\begin{tabular}{|c|c|c|c|}
\hline & 3 year-olds $(n=616)$ & 4 year-olds $(n=602)$ & 5 year-olds $(n=555)$ \\
\hline & $\mathrm{N} ;$ Weighted \% & N Weighted \% & $\mathrm{N}$ Weighted \% \\
\hline Any disorder & $242 ; 34.4 \%$ & $207 ; 31.8 \%$ & $224 ; 37.0 \%$ \\
\hline Disruptive disorders & $87 ; 10.1 \%$ & $71 ; 9.0 \%$ & $65 ; 9.7 \%$ \\
\hline Attention Deficit hyperactivity disorder & $34 ; 3.7 \%$ & $35 ; 5.1 \%$ & $31 ; 4.5 \%$ \\
\hline Oppositional Defiant disorder & $61 ; 7.0 \%$ & $49 ; 5.2 \%$ & $43 ; 6.4 \%$ \\
\hline Conduct disorder & $10 ; 1.4 \%$ & $2 ; 0.2 \%$ & $5 ; 0.6 \%$ \\
\hline $\begin{array}{l}\text { Mood disorders (including depressive episode } \\
\text { with insufficient symptoms) }\end{array}$ & $22 ; 3.3 \%$ & $12 ; 1.9 \%$ & $12 ; 1.7 \%$ \\
\hline Anxiety disorders & $57 ; 7.5 \%$ & $50 ; 7.4 \%$ & $72 ; 11.8 \%$ \\
\hline Separation anxiety & $18 ; 2.2 \%$ & $12 ; 1.4 \%$ & $8 ; 1.3 \%$ \\
\hline Generalized anxiety & $1 ; 0.1 \%$ & $1 ; 0.1 \%$ & $5 ; 0.6 \%$ \\
\hline Specific phobia & $26 ; 3.5 \%$ & $32 ; 5.2 \%$ & $50 ; 8.3 \%$ \\
\hline
\end{tabular}


Table 3. The comparative discriminative capacity of CBCL-syndrome scales and CBCL-DSM5 scales for disruptive and anxiety disorders in preschool children.

\begin{tabular}{|c|c|c|c|c|c|c|c|c|c|c|c|c|c|c|c|c|c|c|c|c|}
\hline \multirow{3}{*}{$\begin{array}{l}\text { DSM5 } \\
\text { Disorders }\end{array}$} & \multirow[b]{3}{*}{ CBCL-Syndrome } & \multirow{2}{*}{\multicolumn{3}{|c|}{ Internal consistency }} & \multirow[b]{3}{*}{ CBCL-DSM5 } & \multirow{2}{*}{\multicolumn{3}{|c|}{ Internal consistency }} & \multirow{2}{*}{\multicolumn{4}{|c|}{$\begin{array}{c:c}3 \text { years-old }(n=616) \\
\text { CBCL-synd. } \\
\text { CBCL-DSM5 }\end{array}$}} & \multicolumn{4}{|c|}{4 years-old $(n=602)$} & \multicolumn{4}{|c|}{5 years-old $(n=545)$} \\
\hline & & & & & & & & & & & & & $\mathrm{CBCL}$ & synd. & $\mathrm{CBCL}$ & DSM5 & $\mathrm{CBCl}$ & synd. & $\mathrm{CBCL}$ & DSM5 \\
\hline & & Age3 & Age4 & Age5 & & Age3 & Age4 & Age5 & AUC & $\mathrm{R}^{2}$ & AUC & $\mathrm{R}^{2}$ & AUC & $\mathrm{R}^{2}$ & AUC & $\mathrm{R}^{2}$ & AUC & $\mathrm{R}^{2}$ & AUC & $\mathrm{R}^{2}$ \\
\hline$\overline{\mathrm{ADHD}}$ & Attention problems & .654 & .695 & .725 & ADHD & .735 & .771 & .792 & .905 & 25.5 & .901 & 30.0 & .858 & 21.2 & .836 & 19.4 & .819 & 22.4 & .847 & 25.2 \\
\hline ODD & Aggressive behavior & .861 & .863 & .885 & ODD & .736 & .747 & .784 & .845 & 21.3 & .854 & 24.0 & .876 & 35.8 & .867 & 33.0 & .851 & 32.7 & .881 & 39.8 \\
\hline$C D$ & Aggressive behavior & & & & ODD & & & & .860 & 11.2 & .796 & 2.3 & .981 & 29.3 & .920 & 19.1 & .938 & 24.1 & .920 & 14.0 \\
\hline Anxiety & Anxious-depressed & .706 & .712 & .727 & Anxiety & .646 & .650 & .648 & .733 & 12.0 & .746 & 14.2 & .678 & 7.4 & .710 & 6.5 & .732 & 14.9 & .801 & 19.2 \\
\hline Mood & Anxious-depressed & & & & Depressive & .506 & .512 & .595 & .645 & 5.0 & .660 & 5.0 & .687 & 4.6 & .729 & 5.0 & .679 & 1.1 & .630 & 0.9 \\
\hline Mood & Withdrawn & .706 & .681 & .727 & Depressive & & & & .552 & 0.1 & .660 & 5.0 & .657 & 3.32 & .729 & 5.0 & .689 & 6.7 & .630 & 0.9 \\
\hline
\end{tabular}

ADHD: attention deficit hyperactivity disorder. ODD: oppositional defiant disorder.

AUC: Area under ROC curve. $\mathrm{R}^{2}$ in percentage (\%).

Results adjusted by children's sex and other comorbidity. 
Supplementary Material
Click here to download S

Click here to download Supplementary Material: Tittle page.docx 
Supplementary Material
Click here to download Supplementary Material: CBCL1-5-DSM5 Revision Certificate.pdf

Supplementary Material
Click here to download Supplementary Material: CBCL1-5-DSM5 Revision Certificate.pdf

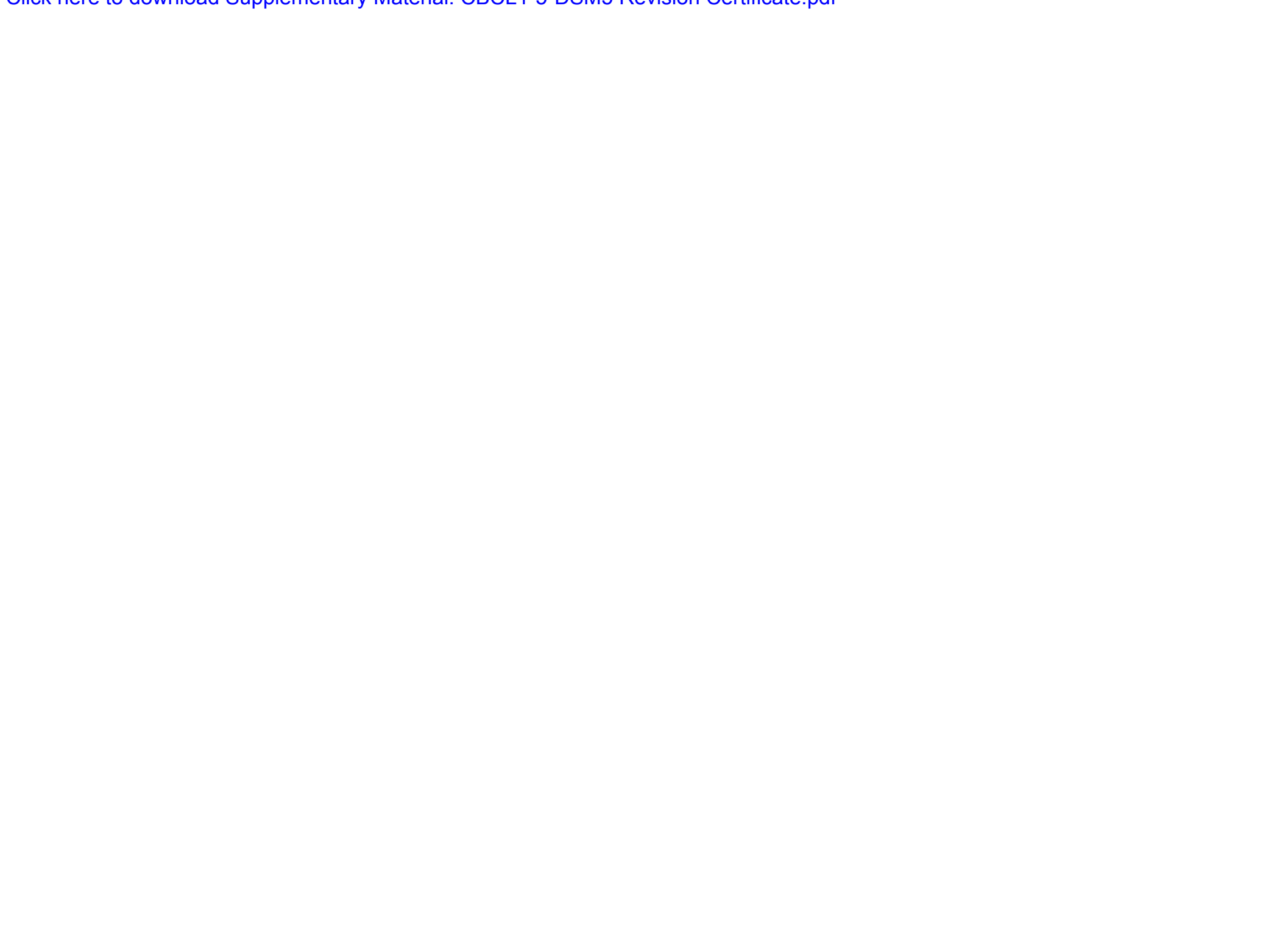

Click here to download Supplementary Material: CBCL1-5-DSM5 Revision Certificate.pdf

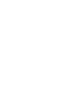
$\sqrt{2}$

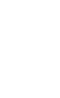
.

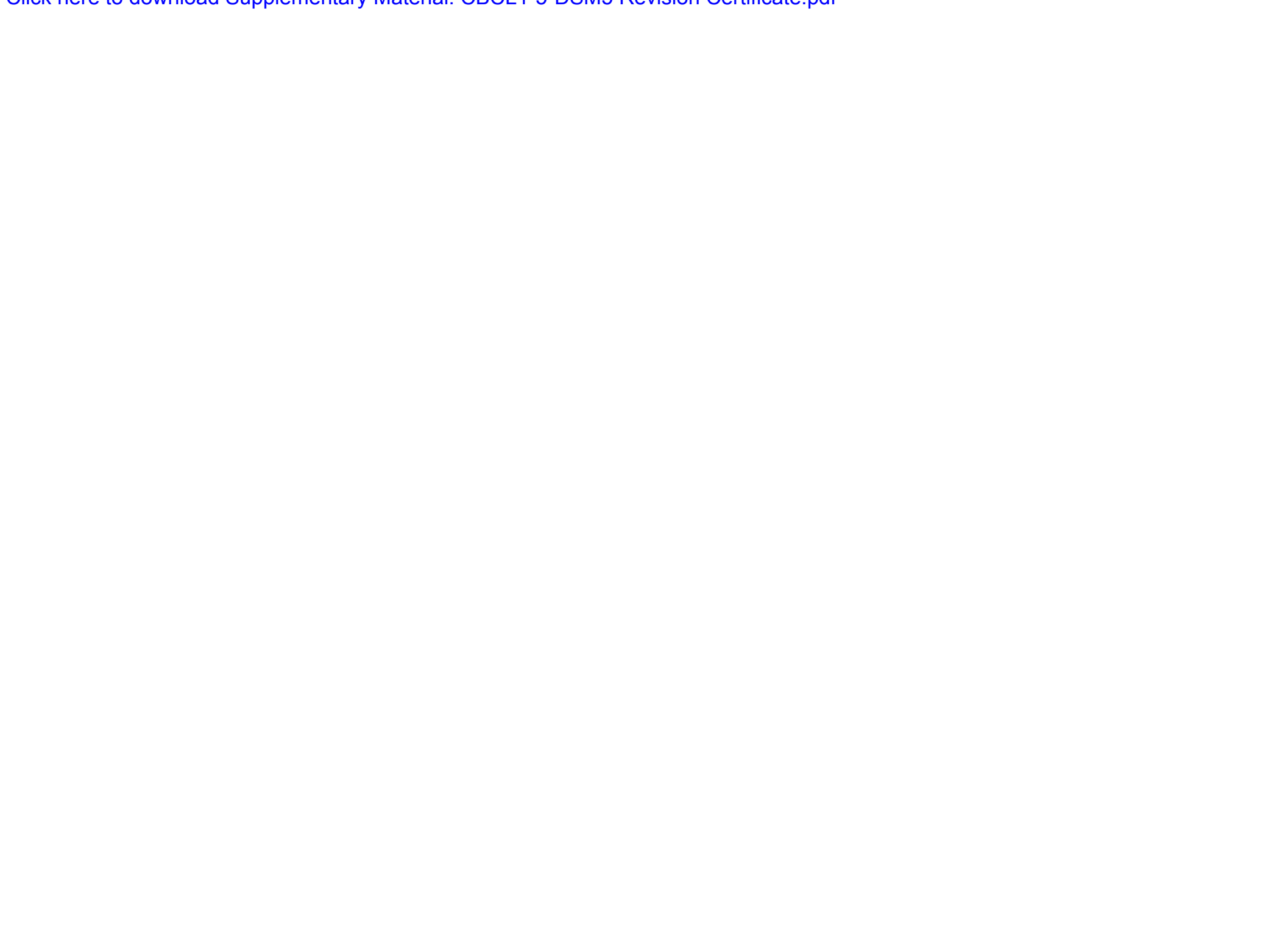

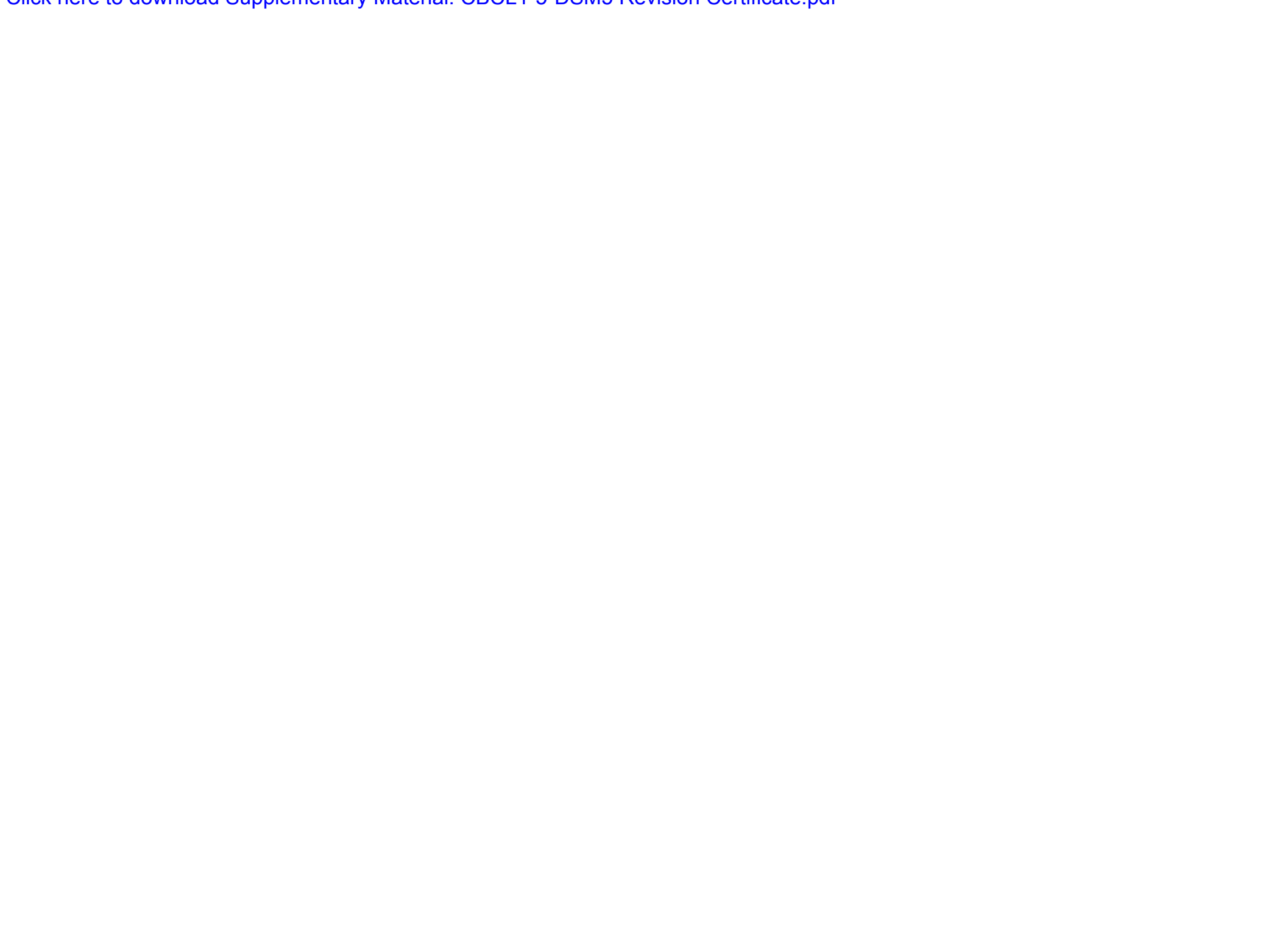

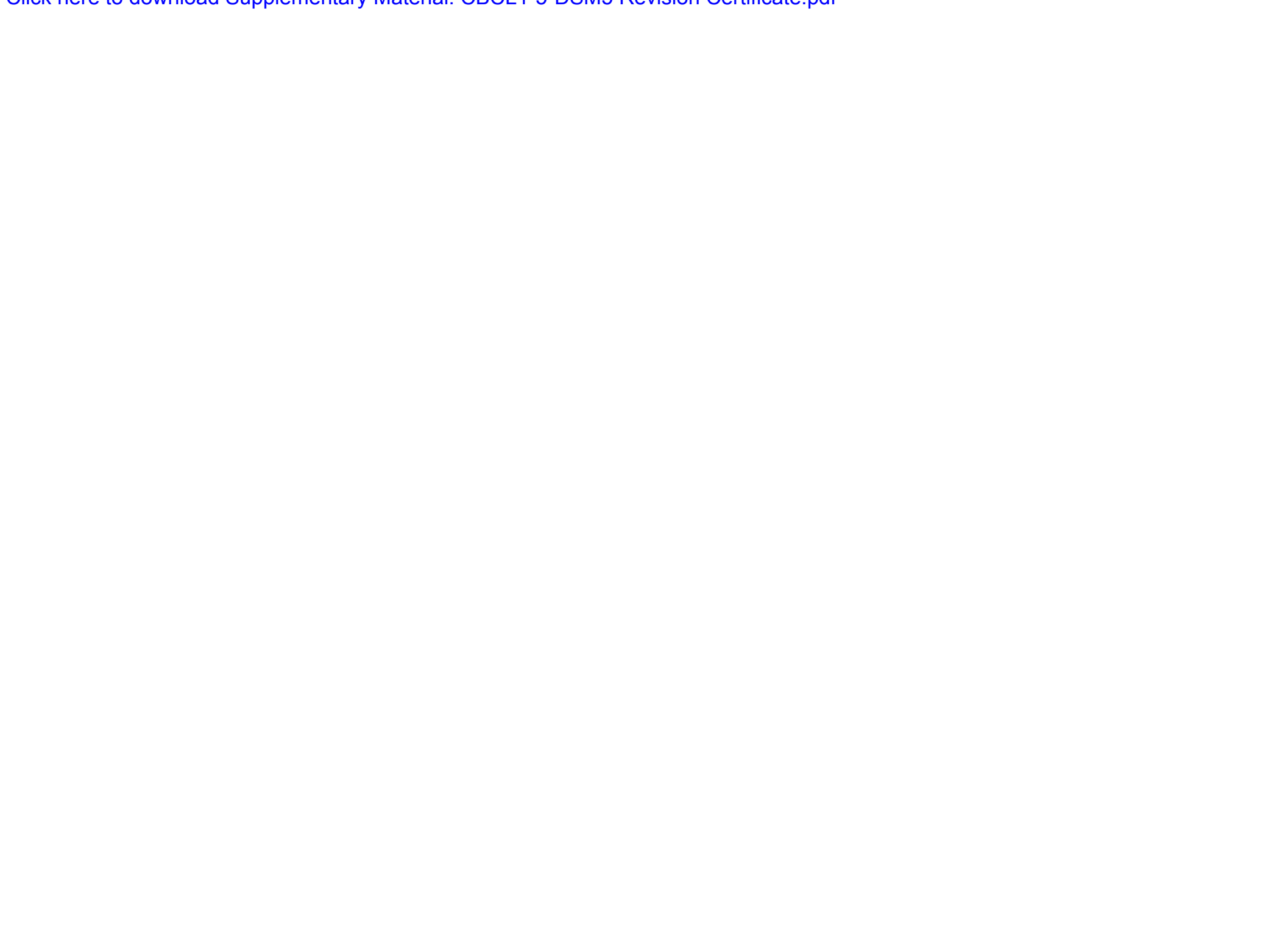

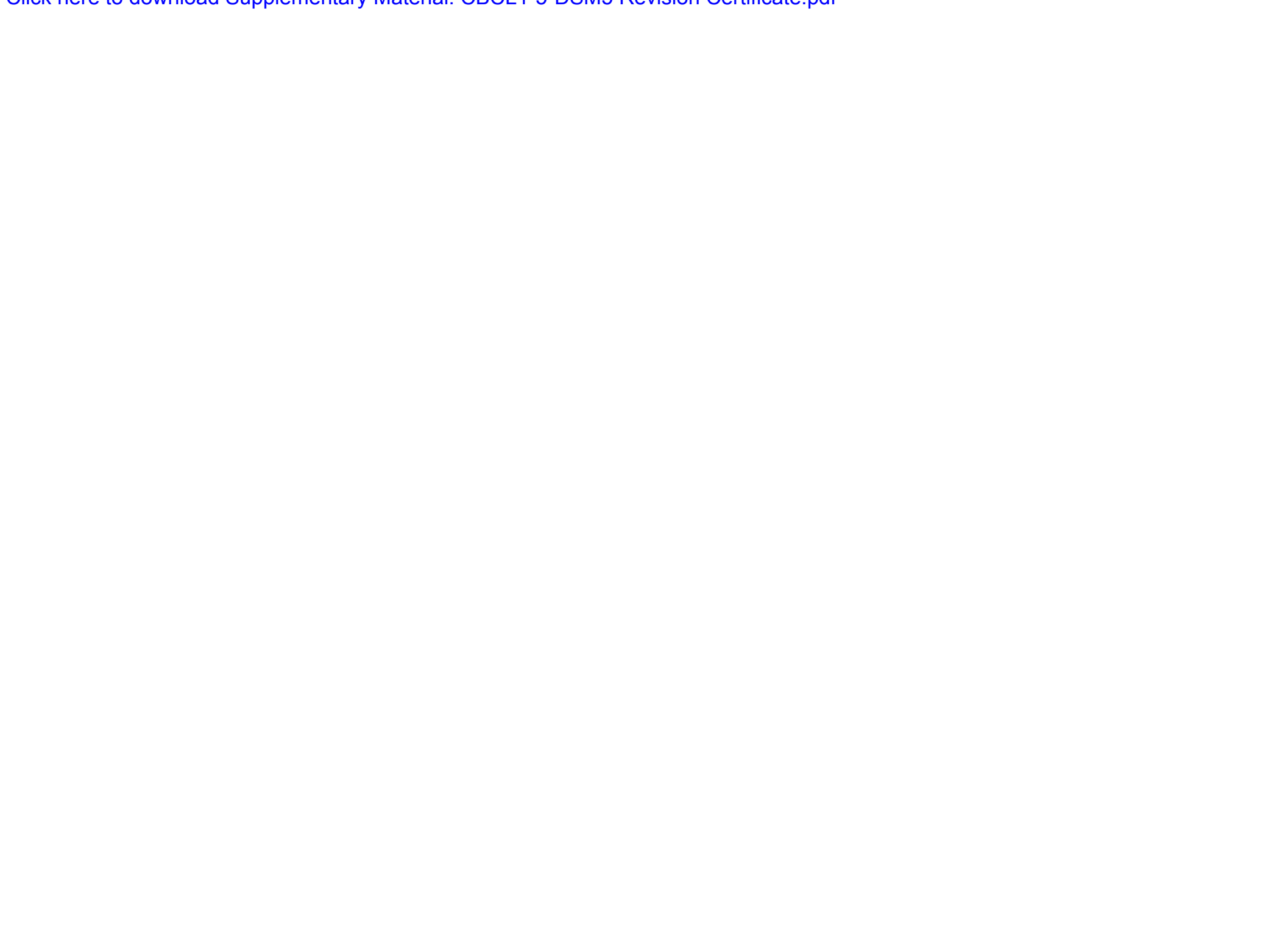

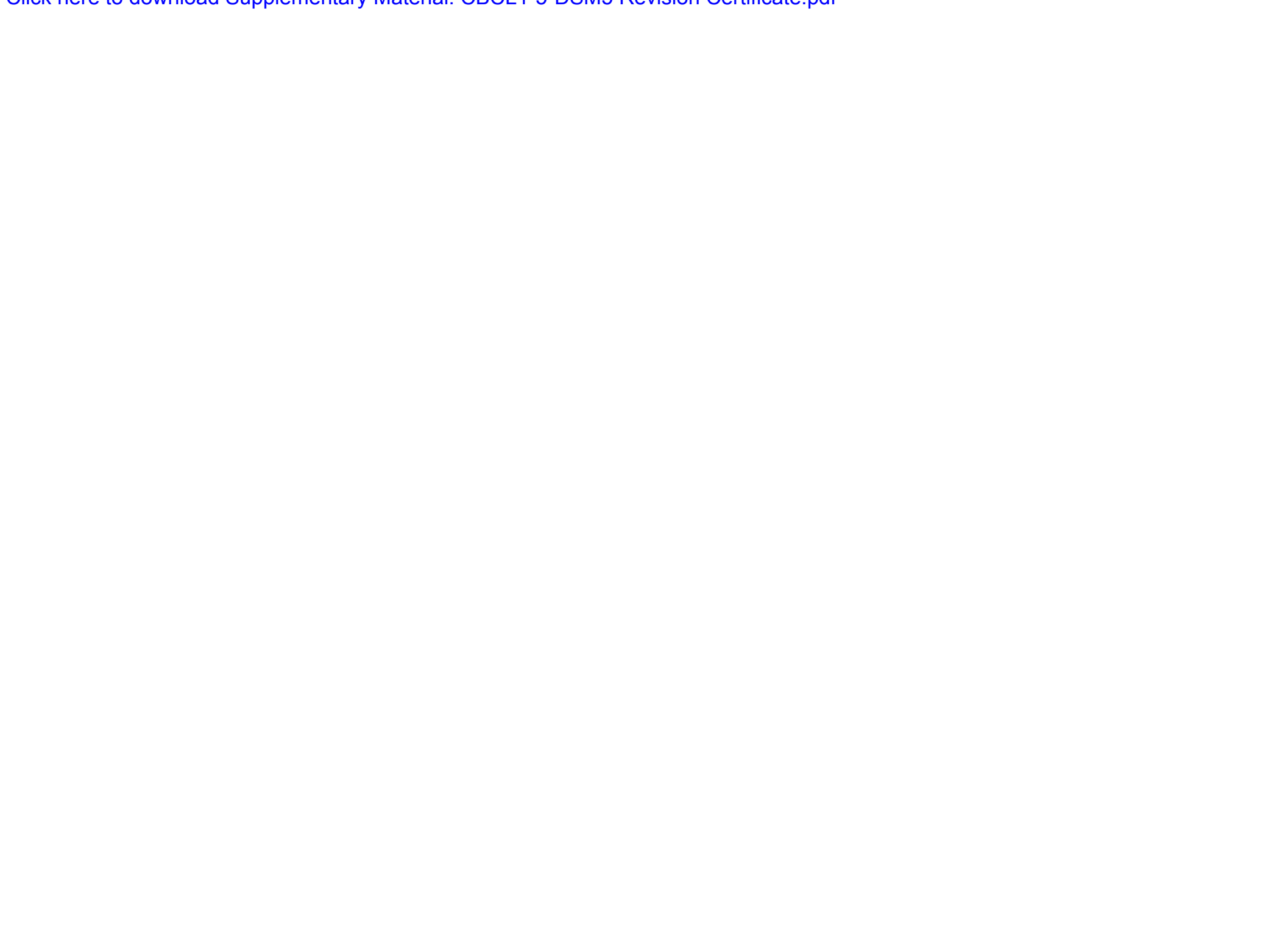
(1)

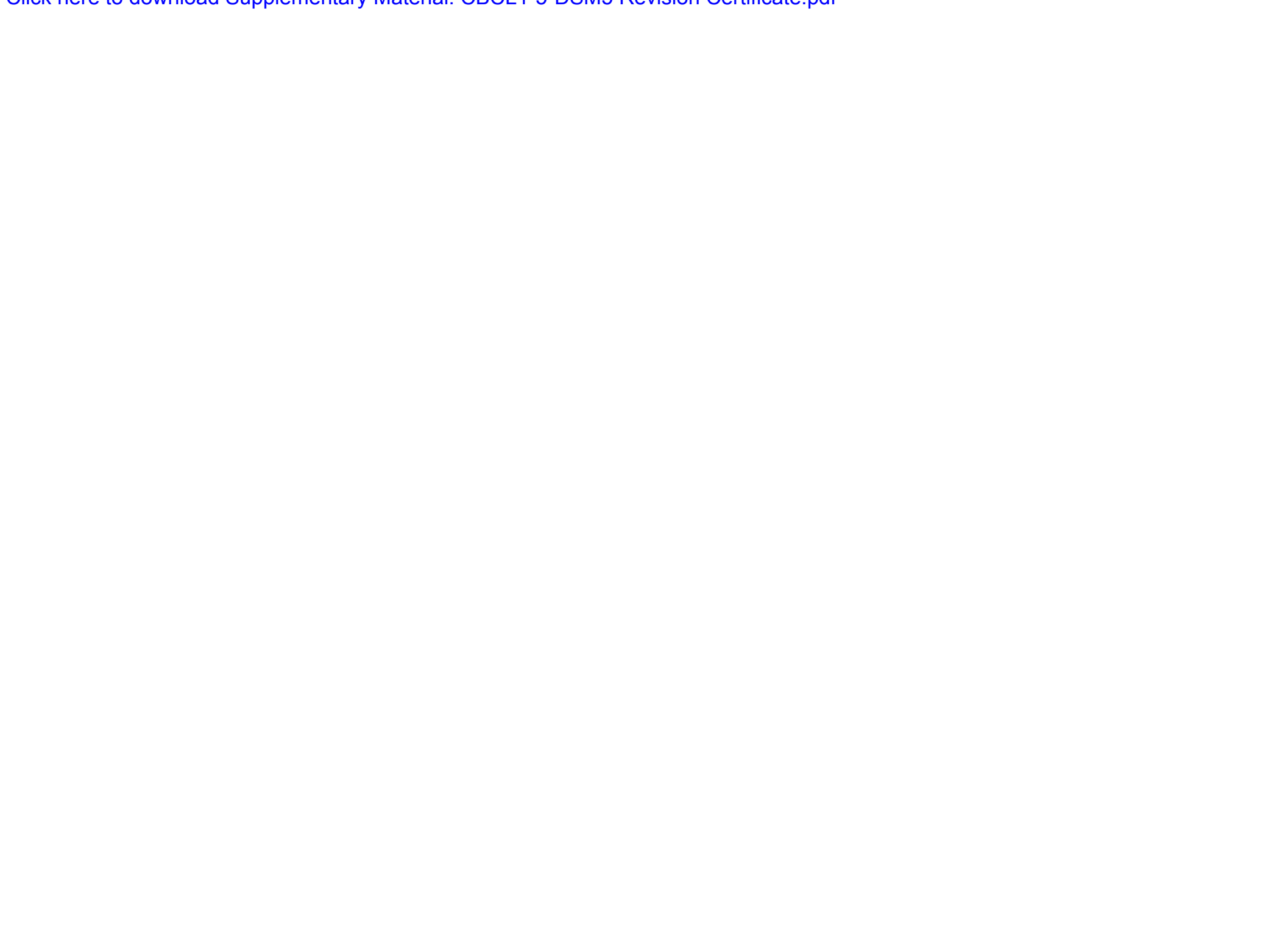
(1) (1) (1) (1) (1) (1) (1) (1) (1) (1) (1) (1)

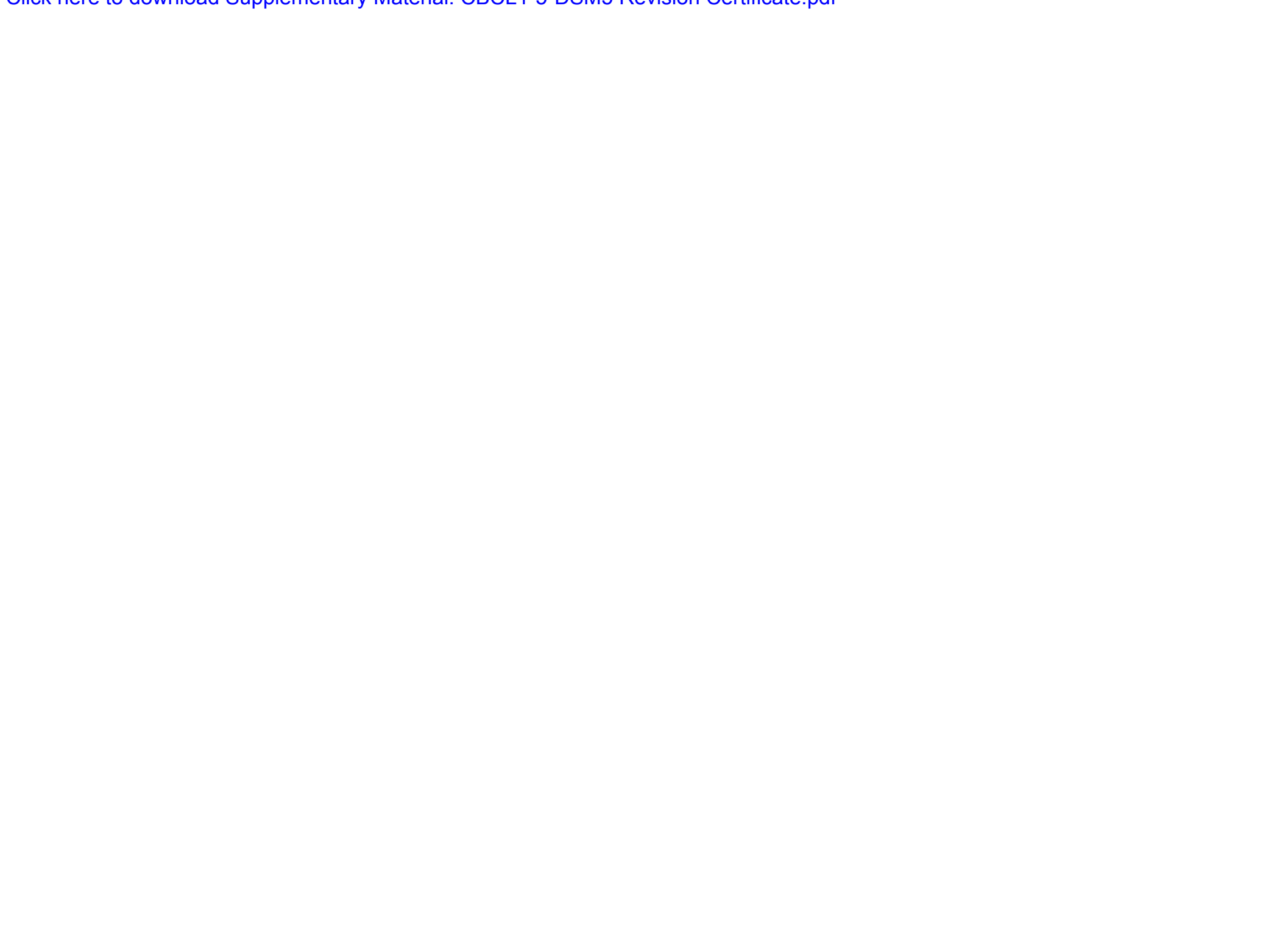
(1) (1)

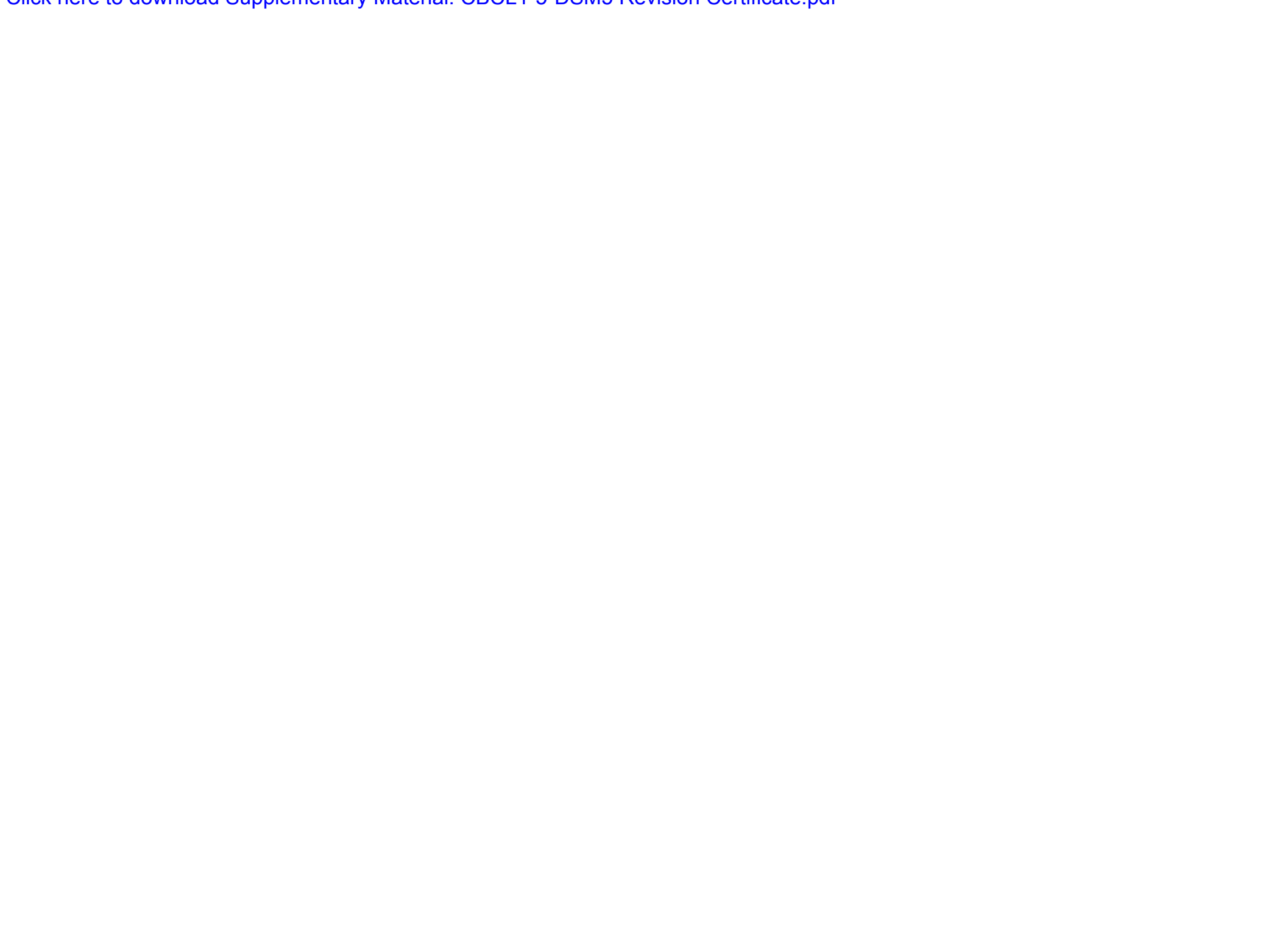
(1) (1) (1)

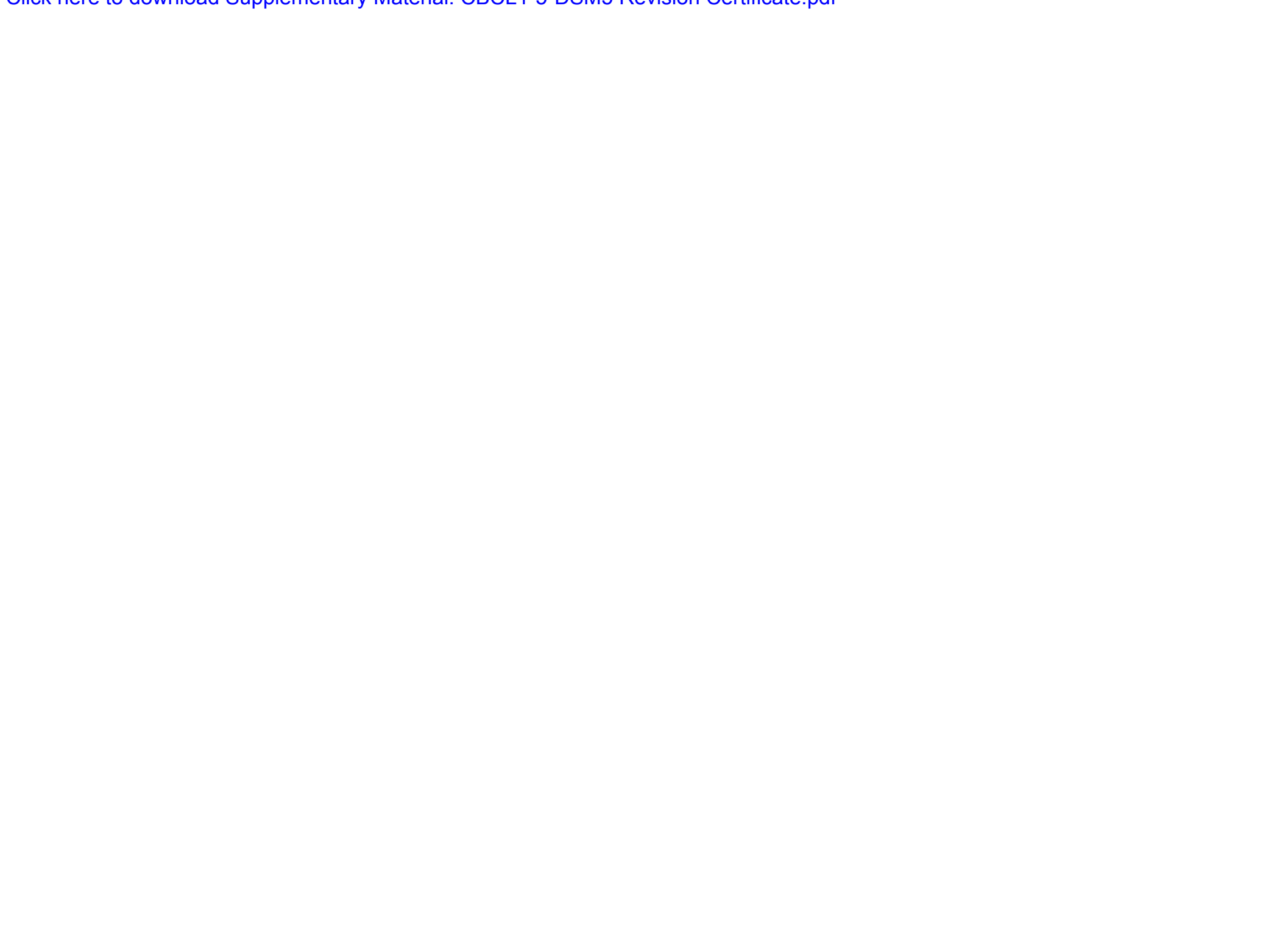

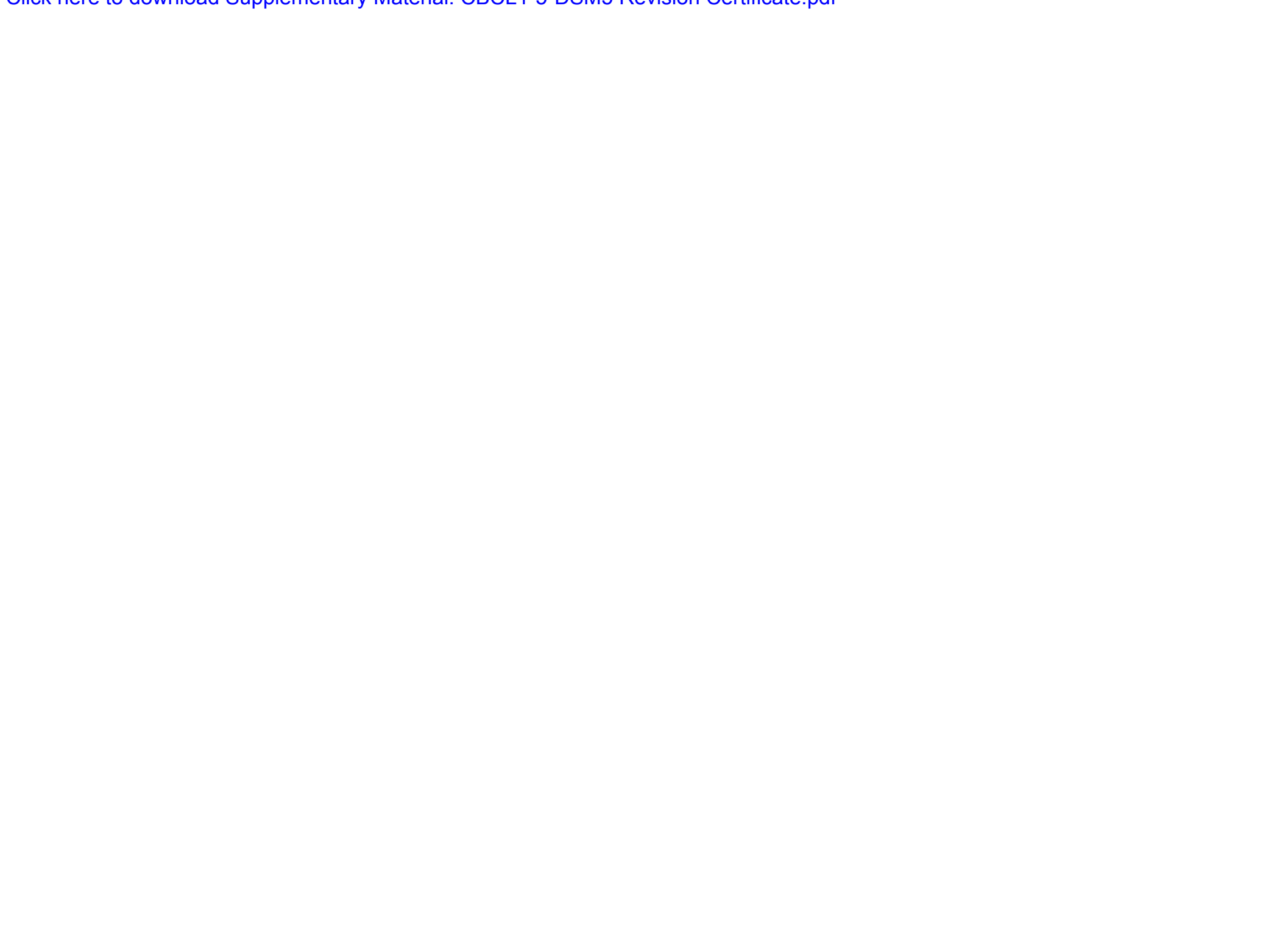

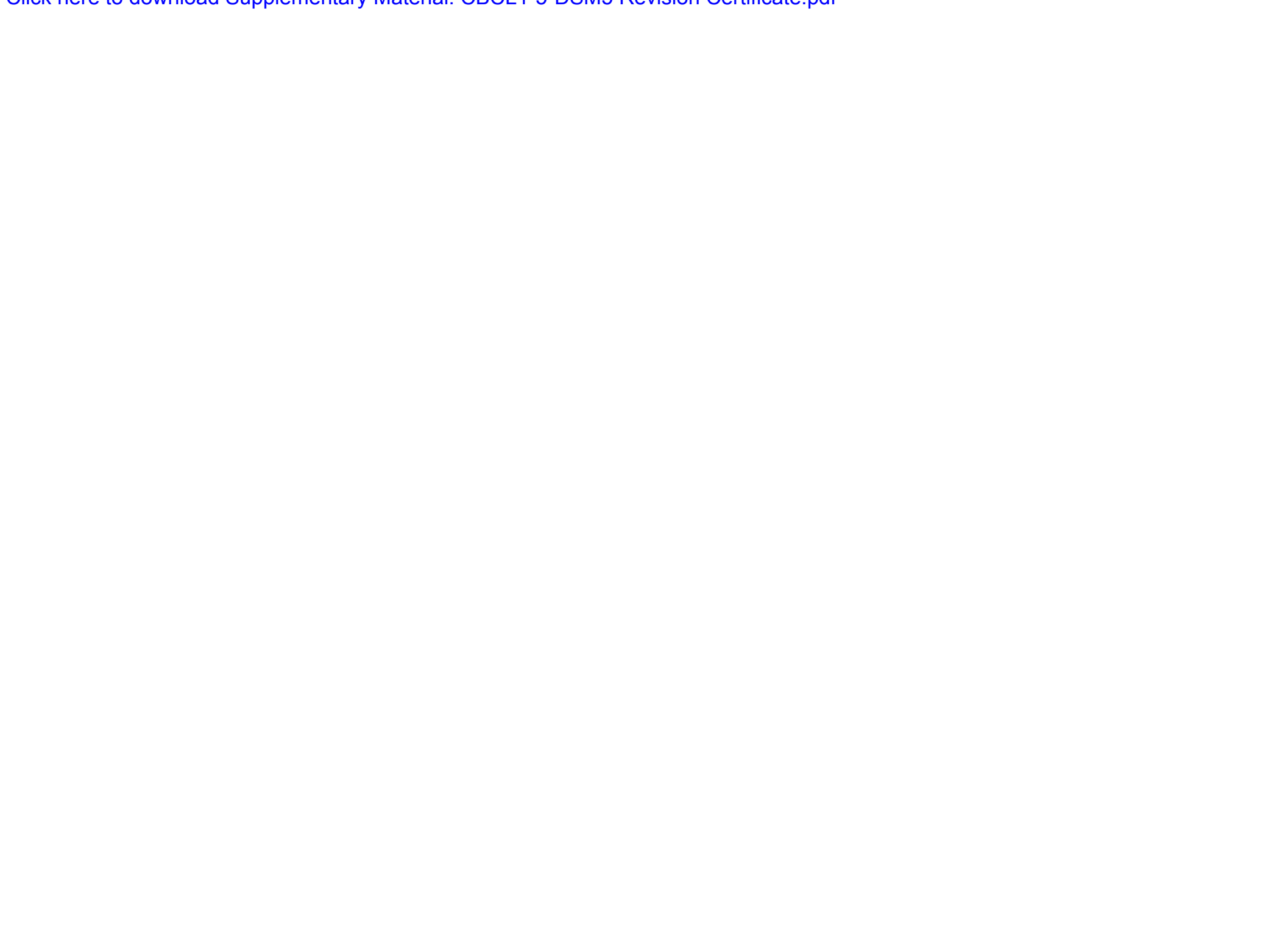

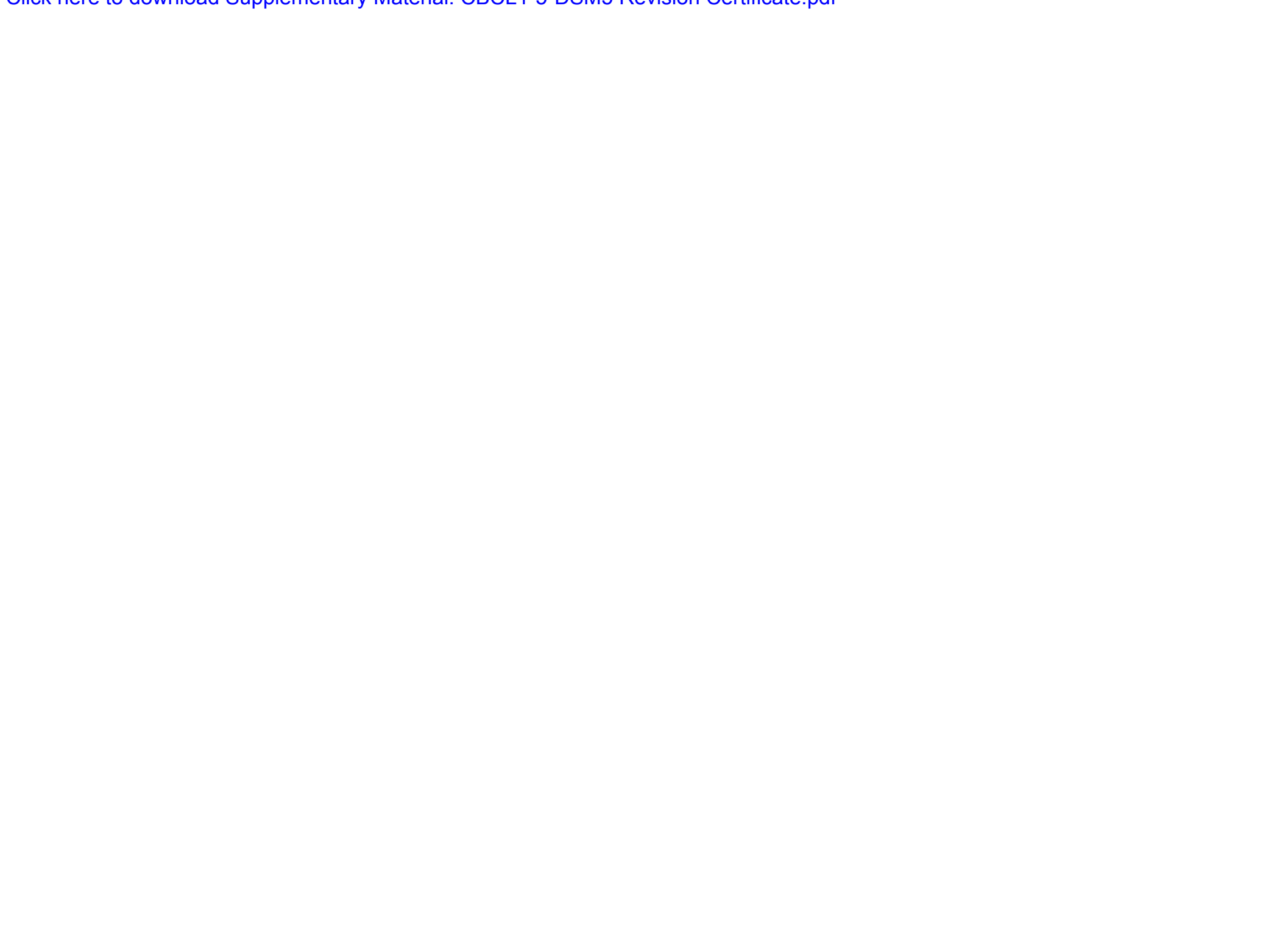

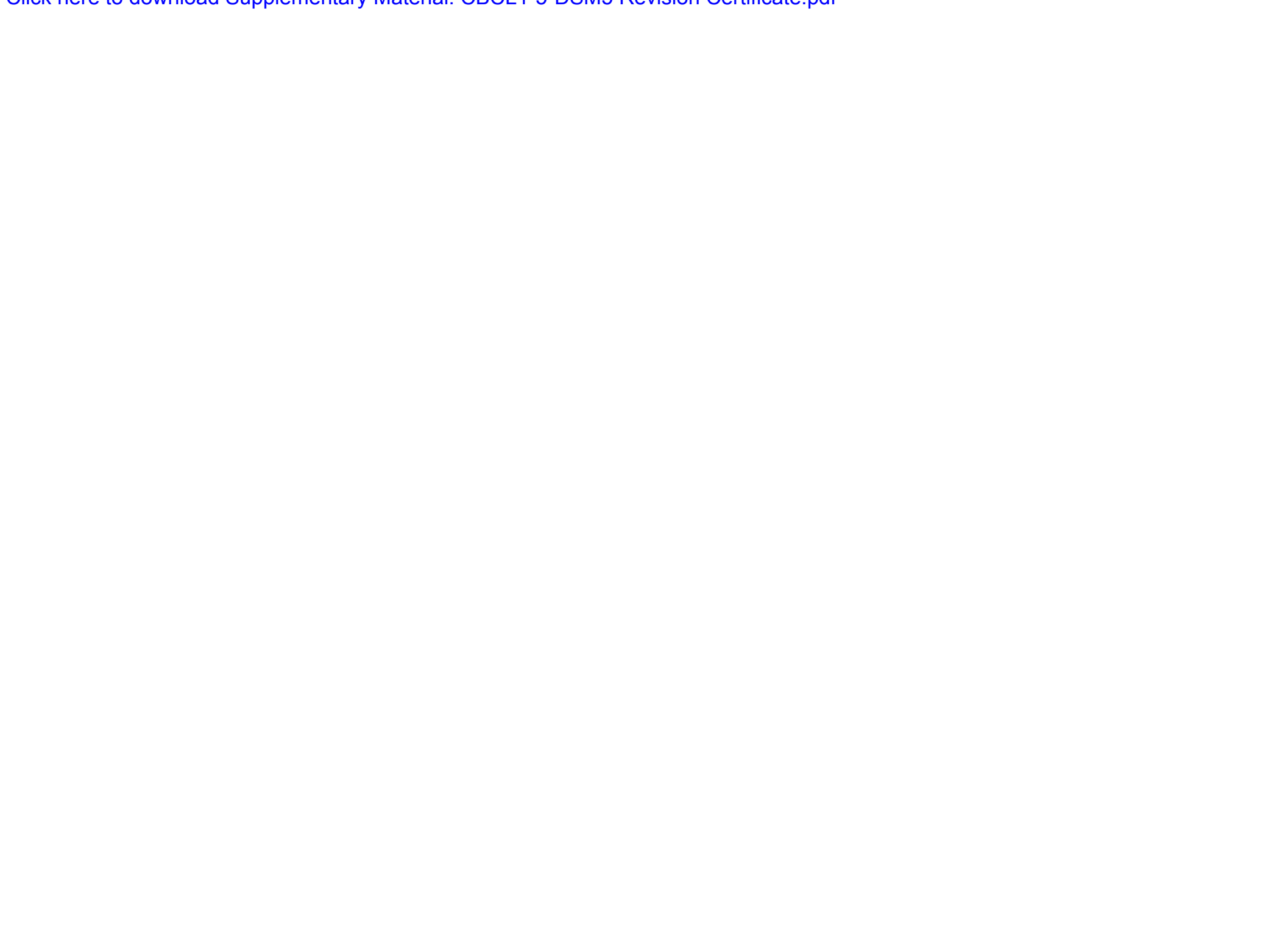

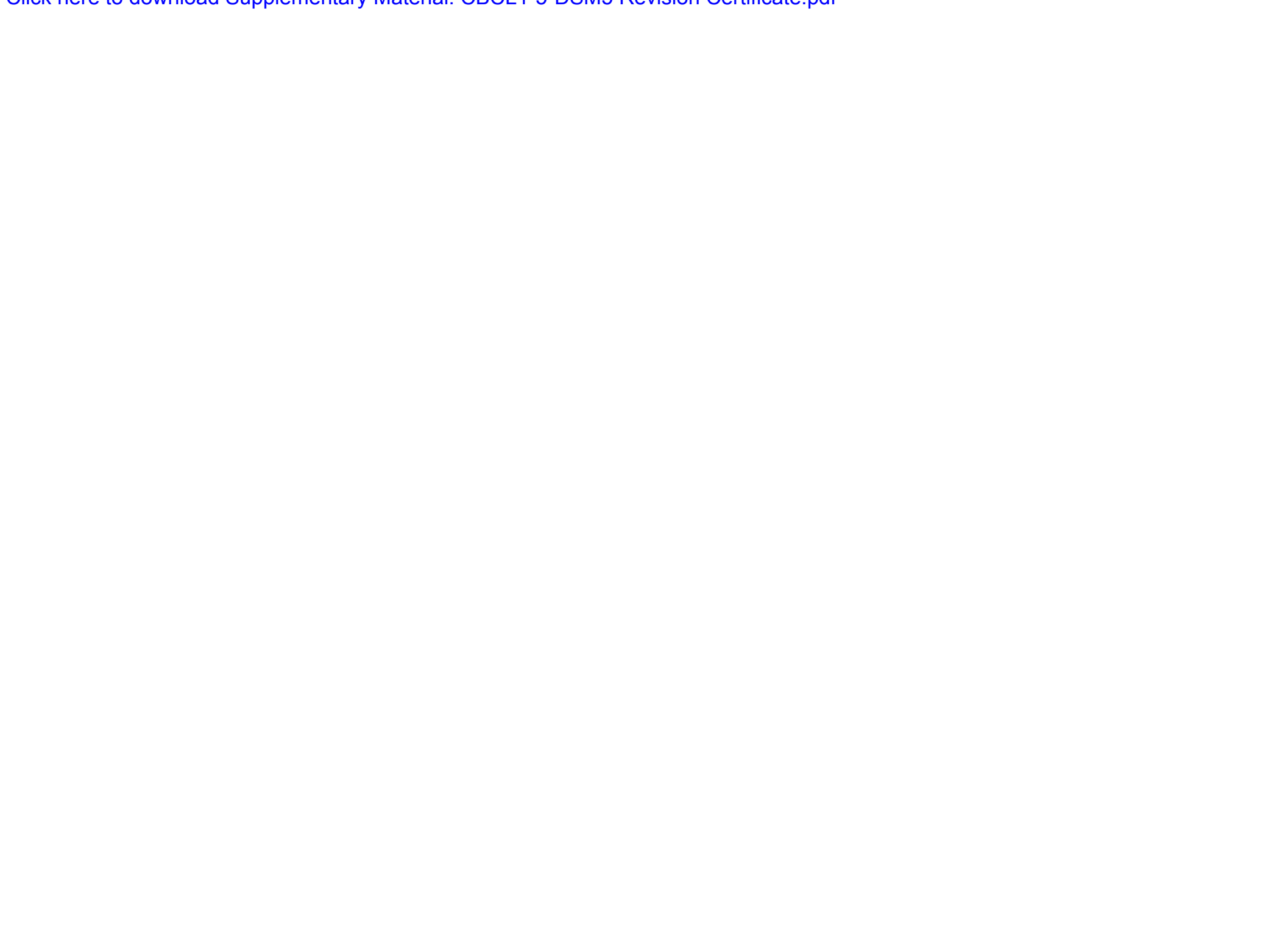

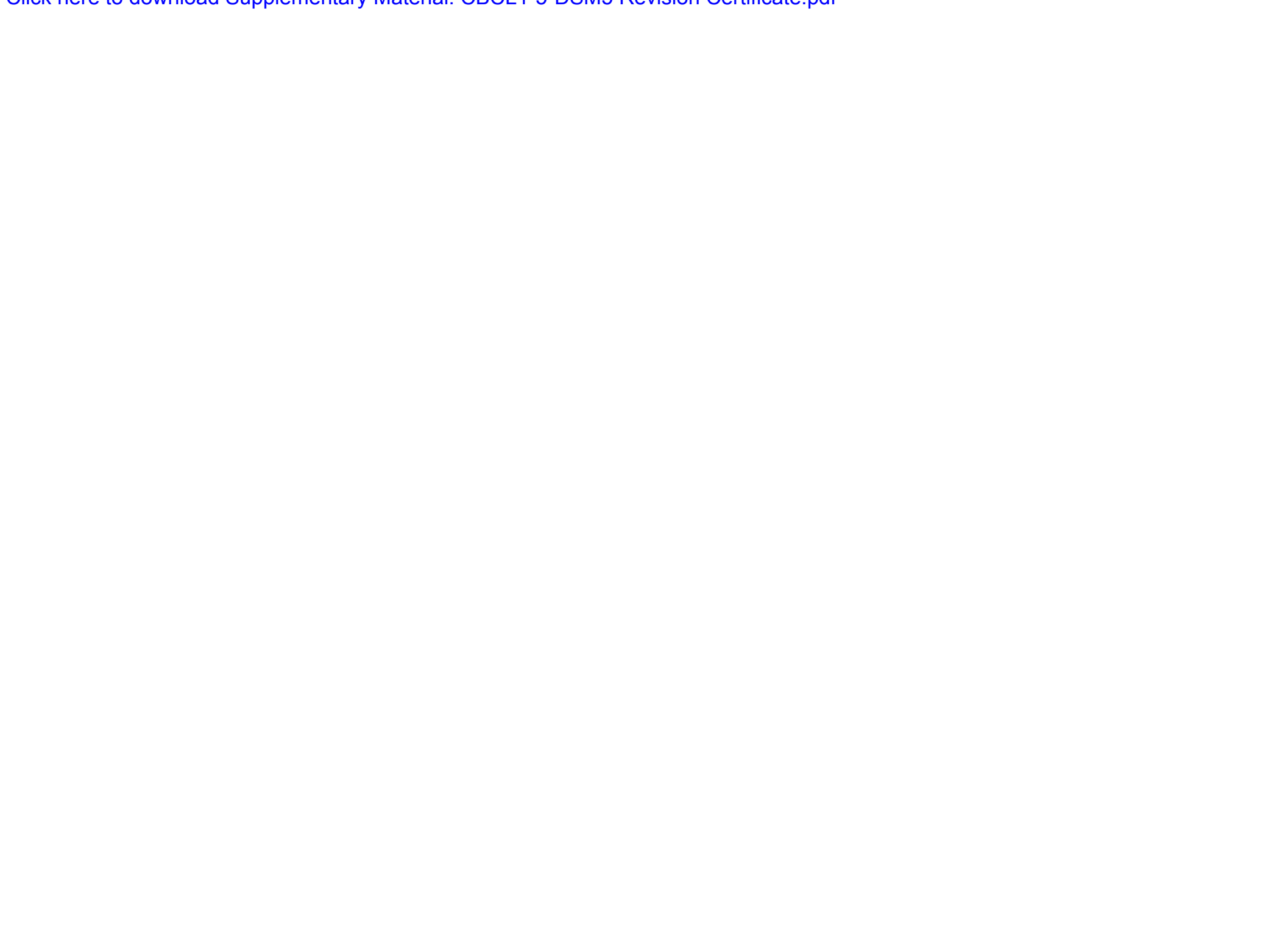

